\title{
The role of intermediaries in establishing a sustainable supply chain
}

Dr Rosanna Cole (corresponding author)

University of Surrey, Guildford, GU2 7XH, UK

r.cole@ surrey.ac.uk

01483683642

Professor James Aitken

University of Surrey, Guildford, GU2 7XH, UK

james.aitken@surrey.ac.uk

01483300800 


\begin{abstract}
In sustainable supply chain management, buyers may use intermediaries to bridge exchanges with suppliers when knowledge of suitable sustainability practices is weak and in need of facilitation. Understanding how supply chain intermediaries perform this role and what happens when intermediation is no longer needed is important to establishing more sustainable supply chains. Two supply chain intermediaries have been investigated with the resulting case study evidence analysed using the Gioia methodology. The findings suggest supply chain intermediaries add value to the buyer-supplier exchange by facilitating sustainability-related information transfer, knowledge development, risk management and improved capabilities. For example, specific practices such as corrective action reports, often managed by the intermediary, underpin the development of a sustainable supply chain. When the intermediary is no longer needed, they become disintermediated from the specific buyersupplier exchange but may be re-employed in a new triadic relationship in the future with previous parties. This provides positive spill-over effects through intermediationdisintermediation-post-intermediation cycles for both the buyer and supplier populations and for broader society. Overall, the findings highlight the value of the transient position of supply chain intermediaries in establishing sustainable supply chains and the intended consequences of their involvement.
\end{abstract}

Keywords: supply chain intermediaries, sustainable supply chains, socially responsible purchasing, sustainable sourcing, sourcing triads.

Category: Research paper 


\section{Introduction}

Sustainable supply chain management (SSCM) is a challenging issue for all actors across the supply chain. The potential influence and negative impact of one supply chain actor on the reputation and performance of other organisations in the chain (Jacobs and Singhal, 2017; Kim et al., 2019), highlights the criticality of establishing SSCM (Hutchins and Sutherland, 2008: Hartmann and Moeller, 2014). One of the principal challenges is the ambiguity of the measures and definitions that exist around sustainability dimensions. This has led to the growth of supply chain intermediary (SCI) organisations which provide platforms for buyers and suppliers to align their supply chain objectives at the sourcing outset (Vedel and Ellegaard, 2013). However, the role that SCIs perform in establishing SSCM is a topic which requires greater understanding and clarity to support organisations in addressing this increasingly important societal issue (Hannibal and Kauppi, 2018).

The implementation of sustainability relies strongly on the purchasing function and selecting appropriate suppliers (Schneider and Wallenburg, 2012). Socially responsible purchasing (SRP) has evolved to consider social and ethical issues advocated by organisational stakeholders (Maignan et al., 2002) to improve business reputation and ensure good business practice through the supply network. Supply chains increasingly serve as critical value chains through which ideas and knowledge flow to and from buyers and suppliers (Wang et al., 2016).

Having the capabilities to clearly translate the needs of both buyers and suppliers is a significant enabling skill of SCIs in supporting this flow (Van der Valk and Van Iwaarden, 2011; Wynstra et al., 2015). Where this knowledge is absent in terms of SSCM practices, SCIs can broker access to potential supply chain partners who have been assessed for their 
sustainability credentials. How SCIs perform this service and the role they play when developing the bridge between firms or beyond, is not evident in the literature (Nakamba et al., 2017). This paper focuses upon the role of SCIs in supporting firms to establish sustainable supply chains (SSCs) at the point where buyers and suppliers are linked for the first time (e.g., SRP), complementing studies where supply chain partners are considered at later stages such as in supplier development (Rodriguez et al., 2016a, 2016b; Hannibal and Kauppi, 2018).

We investigate the changing role of SCIs, leading to the establishment of a SSC by seeking to answer the following research questions:

1. What is the role of the sustainability supply chain intermediary (SCI) in establishing a sustainable supply chain (SSC)?

2. How does the role of the SCI change during the course of establishing a SSC, and why?

The main contribution of our study highlights how the SCI's role at the sourcing stage provides a pathway for SSC development. The role attributes of the SCI, the nature of the temporary triad and the intended consequence of their transient position lead to wider SSC practice in the network. Development towards better sustainability in supply chains is meaningful to both sustainable business models and wider society, which benefits from spill over effects. Where buyer and suppliers are linked for the first time, at the sourcing stage, meaningful insight into how to initially establish SSCs is valuable. To advance SSCM practice, empirical, qualitative case-studies which uncover the transformative process of how to make supply chains more sustainable are needed (Akhavan and Beckmann, 2017). Using case study research, we provide seven propositions to generate a theoretical contribution to 
the role of the SCI and how and why their role changes through stages of the sourcing process.

This paper is laid out as follows. In the next section we review three strands of literature; SSCM, SCIs and SRP are introduced to support the investigation of the SCI within the context of SSCs. This is followed by an explanation of the explorative case study approach that was utilised and the analysis conducted. The discussion explores the contribution of the research and the value adding role of the SCI, how it changes and why, is explained. Finally, the conclusion is presented along with the managerial implications, limitations and future research opportunities.

\section{Literature Review}

\subsection{Sustainable Supply Chain Management}

Mismanaging suppliers in a multi-tiered network can damage a firm's operations and reputation (Kim et al., 2019). SSCM may include multi-stakeholder initiatives that can help to manage complex supplier networks where good sustainability behaviour is crucial. Villena and Gioia (2018) found that many lower-tier suppliers address their environmental and labour issues passively yet constitute the riskiest suppliers in a supply network. Therefore, assistance to improve behaviour is required. Villena and Gioia (2018) found that organisations who are leading in their SSCM pursuits had firstly, created a supportive organisational structure to manage sustainable supply networks, often with the use of multi-stakeholder initiatives and secondly, invested in building sustainability capability for their suppliers. Their suppliers recognised these learning opportunities as major drivers of their own sustainability agendas. 
The multi-stakeholder initiatives and use of SCIs help to tackle social and environmental challenges to improve SSCM and encourage tier-one suppliers to do likewise by cascading their sustainability requirements throughout their supply networks (Cole, 2017). Villena and Gioia (2018) lastly noted that if suppliers do not improve their sustainability credentials "they will soon experience the real sustainability risks to which they are exposed-not just some vaguely conceived public disfavour, but termination of contracts and even loss of operating licenses".

\subsection{Sustainability Supply Chain Intermediaries}

A SCI is a distinct organisational form that occupies a position in global sourcing and supply chain management (Fung and Chen, 2010; Vedel and Ellegaard, 2013). Often part of a multistakeholder initiative, roles may include agents, trading houses, international purchasing offices or third party assessors. Different intermediaries may take on different roles and business scopes along the supply chain but generally add value in some way (Feng and Chung, 2010), and mostly through reducing risk (Vedel and Ellegaard, 2013; Villena and Gioia, 2018). Sustainability SCIs through their network-driven, not-for-profit, structures can offer a one-stop-shop for both buyers and suppliers. For purchasing organisations, the SCI aims to reduce risk, protect the buying organisation's reputation and improve supply chain practices by managing data from suppliers with the purpose of improving practice where sustainability shortfalls occur. For suppliers, logging information with SCIs eases the burden of having to complete multiple audits, questionnaires and certifications for prospective buyers. Where suppliers can demonstrate their social sustainability credentials and have the opportunity to partake in robust assessment, access to new markets is more likely and more successful (Hannibal and Kauppi, 2018). 
Attempts to define guidelines and a list of appropriate social criteria for suppliers has come from the amalgamation of a variety of direct and indirect sources such as global conventions and SCIs themselves (Leire and Mont 2010; Genovese et al. 2013). For buyers there is no agreement on what should be included and how the data should be collected to operate and manage their supply chains (Leire and Mont, 2010), so many turn to SCIs for help (Vedel and Ellegaard, 2013). SCIs have attempted to fill the knowledge void through developing their own frameworks and guidelines, as well as managing the supplier self-assessment process for purchasers and developing corrective action reports (CARs) for suppliers (Cole and Aitken, 2019). The buyer, SCI and supplier form a triad at the initial stages, structurally consisting of three nodes and the potential links between them. In the sourcing triad, previously disconnected links begin to interact through the support of the SCI (Modi et al., 2015).

Very little research has focused on the role of SCIs in supporting the establishment of a SSC at the purchasing stage. Understanding the not-for-profit SCI role in a sourcing triad, as it develops to establish a SSC, needs investigation to identify the value add of the role. This is because it differs from other profit-making SCIs whose primary objective is to manage risk, because the effects on global sustainability are far wider reaching with longer term effects than simply commercial risk management between businesses. Although sustainability pursuit and the involvement of multi-stakeholder initiatives may have begun as a result of external pressures and expectations, research to further understand organisations and supply chains that have goals other than profit maximisation are needed (Rodriguez et al., 2016b), beyond post-exchange supplier development programmes (e.g. at the start of the relationship). Embedding and integrating social sustainability practices in an organisation's operations is as important as identifying "specific practices facilitating social sustainability implementation" (Nakamba et al., 2017:530). 
The collaborative platform gives access to information and resources for the network members therefore developing a network structure that enhances the capacity and competitiveness of its users (Dyer and Hatch, 2006; Zhang et al., 2015). The harvesting of information from multiple sources and different levels of the supply chain supports SCIs in being the vanguard of changes in the wider community including governments, universities, industry forums as well as businesses, because the private sector has struggled at leading these efforts (Rodriguez et al., 2016b). Examples of sustainability SCIs include not-for-profit organisations such as Sedex, Ecovardis and Maplecroft, though they are scarcely mentioned in the academic literature. In fact, Hannibal and Kauppi (2018) is one of the few studies to utilise empirical data collected across these types of SCIs rather than focussing on the buyer and/or supplier. They provide insights into the position and assessment focus of SCIs, but do not investigate how and why the role of the SCI changes.

SCIs hold a broker position to enhance the network in which they operate because brokering is a mechanism which can create change and value through connecting two disconnected nodes in the network ( $\mathrm{Li}$ and Choi, 2009). SCIs create links between nodes through providing a conduit for information exchange (Figure 1). Thus, research into buyers who develop measures and controls to manage the exchange with intermediaries to minimise the risk associated with the SCI position (Johnson, 2004; Zhang et al., 2015) is not relevant here, as these studies are based on the agency perspective of minimising moral hazard from other commercially driven organisations (Wuyts et al., 2015). Not-for-profit SCIs challenge this basis for them having to be managed through an agency mechanism. Gaining an insight into the operation of the sustainability SCIs and how they manage their platform to develop buyer and supplier capabilities will contribute to the understanding of how SCIs can add value to the exchange and support the establishment of a SSC. 
Figure 1: SCI position in sourcing triad for socially responsible purchasing (derived from Li and Choi, 2009)

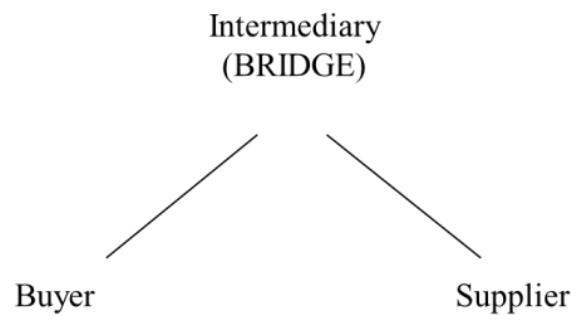

Vedel and Ellegaard (2013) identified three types of sourcing intermediaries (sourcing agent, import intermediary and traditional agent) who have different functions relating to risk. For example, international purchasing offices gather information on potential suppliers and import agents coordinate global logistics for their clients. The function of 'general supplier search and selection', as their paper was not linked to sustainability, was attributed to all three agents. Thus their research only provided limited insight into the role of the SCI specifically. The not-for-profit aspect of the SCI in the social sustainability arena accounts for a need to investigate this actor specifically, even though sustainability risk management is still relevant. Despite Vedel and Ellegaard (2013) confirming that the sourcing intermediary is a growth market, there has been a lack of SCI research published since their paper, confirmed by Hannibal and Kauppi (2018). More focus has been put on NGOs and multistakeholder initiatives assisting with supplier development after a supplier selection has been made and the parties have been commercially linked; the exception being Cole and Aitken (2019) who consider supplier development activities as a pre-requisite to transactional exchange between buyers and suppliers. The SCI's role in SRP which leads to improved social sustainability in the rest of the chain has not been a prominent focus in the literature, 
which is an oversight due to the extent to which they are used in industry and their effects on the rest of the commercial partnership within and beyond the dyad and into the network.

The literature is largely saturated with 'why' we need to operate in an environmentally and socially sustainable way, but is deficient in 'how' it should be done. Understanding the role the SCI adopts and its value to network members is important in comprehending a SCI's ability to support the establishment of a SSC. This is an area that will be explored through the illustrative case studies of 'social' SCIs. The lack of clarity and specific information on how an organisation can build a systematic approach for incorporating, improving and measuring sustainability aspects has led to SCIs offering a supportive platform to facilitate the development of SSC. Understanding the role SCIs play in bridging this gap and how they succeed is currently missing from the SSCM literature.

\subsection{Socially responsible purchasing}

SRP as part of SSCM can be defined as the inclusion in purchasing decisions of the social issues advocated by organisational stakeholders' (Maignan et al., 2002:642). Social sustainability includes matters of poverty, human rights, child labour, health and safety issues, workers' rights, wages, diversity, workforce issues related to disabled workers, racial equality, minorities, equal opportunities, community, corruption and product safety. Socially SSCM ensures working practices of network members do not detrimentally affect any stakeholders; from workers directly involved in the business to the wider community (Huq et al., 2016). To be sustainable, social criteria need to be included in purchasing policies which determines supplier selection (Seuring and Müller, 2008; Leire and Mont, 2010; Zorzini et al., 2015). By extending social responsibility initiatives and accountability beyond the buyer and into the supplier network as a mode of operation to ensure good business practice, organisations can improve their overall corporate social responsibility reputation and record. 
Nakamba et al. (2017) in their recent review of social sustainability in supply chain management literature found that the interest in addressing social sustainability is still relatively recent. Reasons for this are that firstly, social sustainability criteria are ill-defined and difficult to measure, yet are important in terms of reputational associations (Park-Poaps and Rees, 2010; Hartmann and Moeller, 2014). The broad lists of criteria highlight the challenges and confusion around measurements that should be deployed in establishing a SSC. For example, the ITC Standards Map (2019) currently shows a prolific 236 sustainable supply chain standards for organisations to follow. Secondly, reporting on social sustainability issues is problematic largely due to the untraceable nature of human experience (Wilhelm et al., 2016).

The considerable debate on what should be measured, how this should be done and the opaqueness of the issues, is compounded by the lack of an agreed framework in which to gauge their importance for both buyers and suppliers. Additionally, many focal firms attempt to improve welfare conditions throughout the supply chain to an acceptable universal level even though cultural embeddedness shapes the role and acceptable norms of suppliers (Wilhelm et al., 2016). Family life, religion and government regimes develop belief systems that may differ from any universal expectation of social norms and can challenge the realisation of any social supply chain sustainability. When legislation is in place, such as the Modern Slavery Act, organisations still respond differently to standards (Stevenson and Cole, 2018).

Garetti and Taisch (2012) recognise supply chain sustainability as a shift in thinking in many organisations and their supply chains, from models based on old paradigms to options for building new solutions and business models for a better, more sustainable world. SRP is 
gradually being adopted as the advantages of sustainable sourcing are significant (Paulraj 2011). Schneider and Wallenburg (2012) argue that the difference between the potential benefits and actual usage may be attributed to the lack of processes or instruments for its efficient introduction. For example, the concept and its application require significant development in terms of the processes to implement and criteria to control and monitor suppliers (Wagner and Svensson 2010; Xu et al. 2019). Our understanding of the progress of this, facilitated by SCIs, is missing from the literature.

\section{Methodology}

\subsection{Rationale for case research}

The research objective is achieved in the empirical data collection phase using an exploratory, qualitative data analysis methodology advocated by Corley and Gioia (2004) and Gioia et al. (2013). While qualitative and theory building in nature, the coding procedure uses inter-rater reliability (IRR) calculations for statistical agreement by a coding team to determine the reliability of conclusions drawn (as supported by Davey et al., 2010). The

qualitative approach demonstrates transparency in the examination of supply chain intermediation between buyers and suppliers for readers to follow what the researchers have done. Since we were exploring a relatively under-investigated research area in order to build theory, case studies were appropriate (McCutcheon and Meredith, 1993; Yin, 2003). Chen et al. (2017) found in their analysis of methodologies that survey and mathematical modelling are most frequently used to gain better understanding of the practices and performance of supply chain sustainability, with case studies and conceptual research used less frequently. However, they argue that these latter methodologies have the advantage of gaining richer insights and analysis of practices in SSCM. 


\subsection{Case selection}

Case organisations were selected by their SCI engagement relating to sustainability initiatives between buyers and suppliers. There are a small number of social sustainability SCIs operating in the market who act as brokers between buyers and suppliers at the information gathering stage of a supplier selection decision $(<10)$ and two examples of these organisations were used to investigate their role in establishing a SSC. Therefore the sample is taken from a small sampling frame representing around $20 \%$ of the market. SCIs are in a position to provide the most accurate and comprehensive review of buyer and supplier behaviour in the context of the sustainability landscape due to their position in the exchange. By directly examining the SCI, we were able to explore the role that they adopt in establishing a SSC throughout the supplier selection process and beyond. Additionally, we were able to draw conclusions on how the role changes after the buyer and supplier are connected and why that change occurs, developing propositions from our findings, a common result of employing the Gioia methodology (Gioia et al., 2013).

The criteria for the two cases chosen for the study is shown in Table I, which also details the rationale for that selection and how it contributes to the study. The two SCIs have been chosen as the illustrative cases for the research for two reasons. Firstly, they offer a noncommercial insight into the buyer-supplier connection as they are positioned in the middle of the exchange and so have a 360 degree view of the procedure, meaning they have unique insight into the emerging phenomenon. Secondly, their role in the process is of interest, both in terms of their current involvement, future involvement and impact on SSCs generally.

The SCI cases, who focus on social sustainability factors in their service offerings, have pseudonyms of InfoOrder and SociSense. Each SCI is active in the market and promotes the accessibility of their platform for buyers and suppliers to engage with, by attending exhibi- 
tions, conferences and industry colloquiums. One member of the research team met agents from the SCIs through partaking in industry roundtables which provided a point of access into their organisations. Following an analysis of their websites and media activity, the research team discerned that both SCIs were actively enhancing the sustainability endeavours of their partners by promoting the good they do and the benefits to businesses. Selecting these SCIs with a presence in the market allowed for in-depth discussion about their role in a wider network. The unit of data collection in this study is the SCI, while the unit of analysis is the role of the SCI.

Table I. SCI case selection criteria

\begin{tabular}{l|l|l}
\hline Criteria for case selection & Defined by & Rationale \\
\hline $\begin{array}{l}\text { Global, network driven, not- } \\
\text { for-profit operating structure. }\end{array}$ & $\begin{array}{l}\text { Work across four continents and } \\
\text { must not operate for profit. }\end{array}$ & $\begin{array}{l}\text { Ensures that the purpose of the study is } \\
\text { met by investigation into the global, not- } \\
\text { for-profit SCI role. }\end{array}$ \\
\hline $\begin{array}{l}\text { SCI must have a formal } \\
\text { governance structure. }\end{array}$ & $\begin{array}{l}\text { Formal governance structure } \\
\text { must include a Board of Direc- } \\
\text { tors of at least 6 people, tasked } \\
\text { with setting strategic aims and } \\
\text { supervising the management of } \\
\text { the organisations. }\end{array}$ & $\begin{array}{l}\text { Ensures that there are formal systems } \\
\text { and processes in place ensuring the } \\
\text { overall direction, effectiveness, } \\
\text { supervision and accountability of the } \\
\text { SCI. }\end{array}$ \\
\hline $\begin{array}{l}\text { Must engage with upstream } \\
\text { buyers and downstream } \\
\text { suppliers. }\end{array}$ & $\begin{array}{l}\text { A central position between the } \\
\text { two actors. }\end{array}$ & $\begin{array}{l}\text { Ensures that bridging to create a } \\
\text { sourcing triad is possible. }\end{array}$ \\
\hline $\begin{array}{l}\text { SCI's intention must be to } \\
\text { interact with the buyers and } \\
\text { suppliers in equal measure. }\end{array}$ & $\begin{array}{l}\text { Work undertaken is done so } \\
\text { collaboratively with buyers and } \\
\text { suppliers and not for one actor } \\
\text { only. }\end{array}$ & $\begin{array}{l}\text { Ensures that investigation into the role } \\
\text { covers all interactions equally. }\end{array}$ \\
$\begin{array}{l}\text { SCIs must have a focus on } \\
\text { driving SSCs, rather than } \\
\text { simply performing brokerage } \\
\text { for general purchasing } \\
\text { decisions. }\end{array}$ & $\begin{array}{l}\text { Disclosure on website and in } \\
\text { organisational objectives. }\end{array}$ & $\begin{array}{l}\text { Ensures that the SCI role being } \\
\text { investigated is linked specifically to } \\
\text { delivering improved SSCM and not just } \\
\text { to connect buyers and suppliers for } \\
\text { transactional exchange. }\end{array}$ \\
\hline
\end{tabular}

\subsection{Data collection (research instrument and protocol)}

We used a semi-structured interview protocol which was guided by the research questions generated from the literature review. The detailed interview protocol is available in Appendix 
A. By using a purposive sampling technique we ensured that appropriate informants were selected, who could provide plentiful information which can be considered more important than the number of interviewees (Saunders and Townsend, 2016). Using this perspective, informants with sufficient knowledge and experience in the field of supply chain supplier selection decisions and sustainability interests were selected as appropriate interviewees for this study and known as 'knowledgeable agents' (Gioia et al., 2013:17). The individuals targeted within the case organisations were stakeholder relations personnel such as stakeholder managers (4), supplier engagement managers (4), business development managers (5), and business relationship officers (4), resulting in 17 interviews. Each interview was conducted on site and lasted between 50-120 minutes. Approximately 20 hours of interviews were conducted and 770 pages of documents were coded, including purchasing policies, sustainability reports, guidance documents for buyers and suppliers, publicity evidence and existing selection checklists.

\subsection{Data analysis and coding procedures}

The principles of theory generating based on case studies were adopted (Meredith, 1998), which is to explain the whys underlying the whats and hows. New theoretical constructs were sought to develop propositions (Ridder et al., 2014). In doing so, a priori codes and constructs do not exist as empirical observations are not understood by pre-selected theory (Gioia et al., 2013; Ketokivi and Choi, 2013). The data was subject to first and second coding analysis interpreted using NVivo. The approach advocated by Gioia et al. (2013), was used for its effective ability to theorise from, and present, the data. The method supports a rigorous and coherent approach to data analysis and allows for inductive, recursive analysis of data as concepts and themes emerge. For example, the approach presents both first order concepts (i.e., an analysis using informant-centric terms and codes) and second order themes (i.e., one 
using researcher-centric concepts, themes, and dimensions). Taken together, the tandem reporting of both voices-informant and researcher-allows for a "qualitatively rigorous demonstration of the links between the data" and the induction concept development and theory building (Gioia et al., 2013:18). For improved rigour, open coding which was used to analyse the data by deriving and developing concepts from it by the first coder, was ratified by the second. IRR conduct was important for us to ensure that by coding as a team, the interpretation of constructs were measured more accurately. A record of emergent codes were kept in a codebook (a compilation of the codes, their content descriptions, and a brief data example for reference). Codes can accumulate quickly and change as analysis progresses and NVivo was able to keep a record of this to show the evolving nature of the data analysis. Maintaining this list provides an analytic opportunity to organise and reorganise the codes into major categories and subcategories. To demonstrate rigour and transparency, we employed IRR statistics using the Kappa coefficient.

Firstly, the coding agreement was visually evaluated using coding stripes against each document and transcript by the two coders once coding had been completed. This provided the opportunity to visually observe any major differences between the first and second coder to analyse IRR (reconciling coding discrepancies through discussion from the same unit of text). Where this occurred, the differences in interpretations were discussed and the codes were either changed or left as they were using coding stripes. The coding team consisted of two supply chain management academics.

Using NVivo, a coding comparison query was run to calculate the Kappa agreement between the two coders. Kappa statistics represent the proportion of joint judgments of fractions in which there is agreement, after chance agreement has been excluded (Cohen, 1960). The up- 
per value, or perfect agreement, is 1.00 (Cohen 1960). Generally a Kappa between 0.61 and 0.80 represents substantial agreement, and a Kappa between 0.81 and 1 indicates nearly perfect agreement (Landis and Koch, 1977). Discussions between coders to reconcile discrepancies occurred for any Kappa coefficient under 0.61 to demonstrate rigour. The coding table is available in Appendix B. This measure has advantages in increasing reliability of interpretation measures of qualitative research using transparent and documented processes, thus strengthening the methodology. This level of precision is sometimes neglected in qualitative data and so the design enhances the process for external users. Validation was achieved internally by sharing interview transcripts with participants to improve credibility. Transferability for organisations using the SCIs is achieved through context-specific results.

The analysis presents Gioia's data structure to show informant-centric codes, the researchercentric second order themes and the aggregate dimensions which contribute to answering the research questions. The cross-case similarities and differences between the two SCIs are also presented to show evidence of in-depth analysis. The IRR statistics are given in Appendix B. The value adding role of the SCI changes as the purchasing process progresses, that is, at the pre-sourcing, during sourcing and post sourcing stage. This is translated into intermediation, disintermediation and post-disintermediation of their role. 


\section{Case Analysis}

Our findings are organised according to the aggregate dimensions identified in Figure 2: value adding role of the SCI, transient nature of the SCI position and the intended consequence of the SCI role. In section 4.2, the results are further figuratively presented showing the process of how the SCI role changes. Propositions which emerged from the findings are presented. 


\section{Reduced information asymmetry}

Less duplication of information

Trusted, controlled management of information

Exchange of targeted, valuable information

SCI acts as a gateway broker

SCI platforms are a conduit for information exchange

Transparency of and access to information is an opportunity

Flow of information is managed

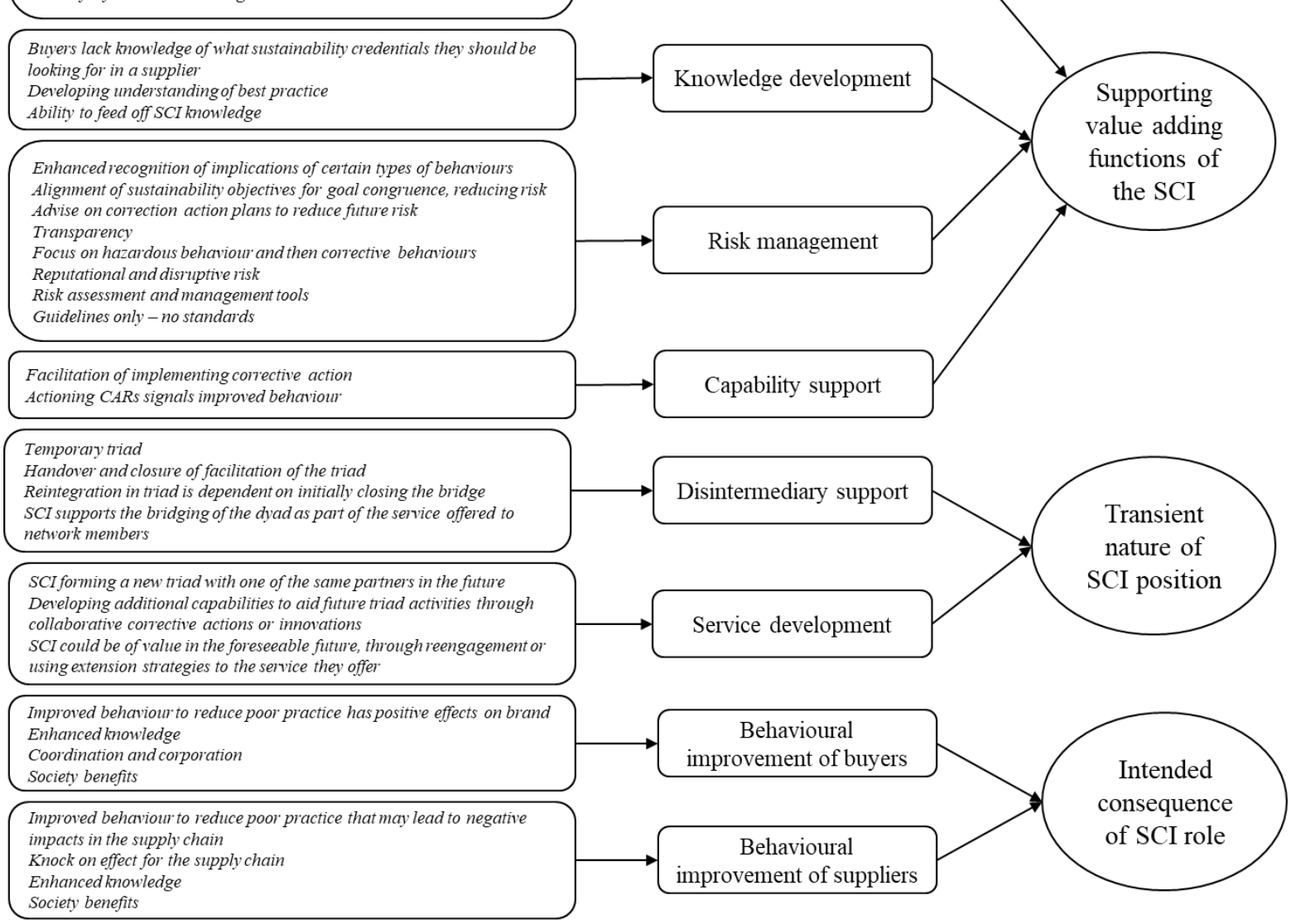

To further supplement Figure 2, Table II shows supporting interview evidence for each second order theme identified in Figure 2 and any cross-case comparisons found. 
Table II: Illustration of coded data for second order themes

\begin{tabular}{|c|c|c|c|}
\hline $\begin{array}{c}\begin{array}{c}\text { Second order } \\
\text { theme }\end{array} \\
\end{array}$ & Supporting evide & SociSense & Cross-case analysis \\
\hline $\begin{array}{l}\text { Information } \\
\text { transfer }\end{array}$ & $\begin{array}{l}\text { "The purpose of our tool is really to make this whole process } \\
\text { more efficient. Instead of those suppliers getting reaudited } \\
\text { endlessly via us they can have one single place where they can } \\
\text { share their sustainability information. Audit information is in } \\
\text { one place shared at multiple times so suppliers do not have that } \\
\text { duplication of effort" Stakeholder Manager }\end{array}$ & $\begin{array}{l}\text { "There are such huge aspects of some } \\
\text { information collected e.g., SAQs that are just not } \\
\text { taken into account by buyers. It can be a blanket } \\
\text { tick box exercise, but whether it's irrelevant to } \\
\text { you or not and it's impossible for you to actually } \\
\text { tick that either way, you still need to do it and } \\
\text { you still need to give us access to that" Business } \\
\text { Development Manager }\end{array}$ & $\begin{array}{l}\text { SCIs manage flow and access to information } \\
\text { between buyers and suppliers to enable them to } \\
\text { trade more easily by mitigating information } \\
\text { asymmetry and providing transparency of } \\
\text { current sustainability credentials. } \\
\text { SCIs report that buyers use data differently to } \\
\text { one another e.g. prioritising different categories. }\end{array}$ \\
\hline $\begin{array}{l}\text { Knowledge } \\
\text { development }\end{array}$ & $\begin{array}{l}\text { "We ask the types of questions that suppliers might be asked in } \\
\text { an audit or something similar but it's basically to help them } \\
\text { understand and help us to understand where they are. It's also an } \\
\text { educational tool. You might have suppliers that are joining } \\
\text { because the [purchaser] has required it but they've never had an } \\
\text { audit before so they might not know what is required. We ask } \\
\text { the questions for some of the things that they should be putting } \\
\text { in place on their site. And there are links to guidance on what } \\
\text { these aspects mean and corrective action reports to improve" } \\
\text { Supplier Engagement Manager } \\
\text { "The data you see there just helps companies to better } \\
\text { understand where they need to prioritise their efforts" Head of } \\
\text { Stakeholder Relations }\end{array}$ & $\begin{array}{l}\text { "It's about making that end to end change for us. } \\
\text { It's a journey from where you are and lets you get } \\
\text { to where you need to be. It's about not being } \\
\text { scared to identify what those problems are. I } \\
\text { think it's a big issue. Retailers and suppliers } \\
\text { cannot be afraid of the truth anymore. Ignorance } \\
\text { is not bliss. You have to identify those scary } \\
\text { problems and you have to be brave, and you have } \\
\text { to try and get some transparency going } \\
\text { throughout the supply chain. It's not going to be } \\
\text { easy but you cannot fix it if you do not know } \\
\text { what the problem is" Business Development } \\
\text { Manager }\end{array}$ & $\begin{array}{l}\text { SCIs manage the development of knowledge of } \\
\text { sustainability requirements for both buyers and } \\
\text { suppliers, sharing market expectations and best } \\
\text { practice. }\end{array}$ \\
\hline $\begin{array}{l}\text { Risk } \\
\text { management }\end{array}$ & $\begin{array}{l}\text { "Reputational risk is damaging to buyers and we mitigate this by } \\
\text { promoting transparency and corrective action to hazardous } \\
\text { behaviour, We can offer an indication of a reliable measure of } \\
\text { risk of potential suppliers based on a buyer's position" Business } \\
\text { Relationship Officer }\end{array}$ & $\begin{array}{l}\text { "Our buyer members reduce their risk by having } \\
\text { access to lots of sustainability information they } \\
\text { can then assess against. Our suppliers want repeat } \\
\text { purchase and long term relationships for } \\
\text { continuity of supply and by having the } \\
\text { opportunity to showcase their strong } \\
\text { sustainability areas and demonstrate } \\
\text { improvement; they can do this" Business } \\
\text { Relationship Officer }\end{array}$ & $\begin{array}{l}\text { SCIs contribute to the risk management efforts } \\
\text { of buyers and suppliers by aligning } \\
\text { sustainability expectations and objectives (goal } \\
\text { congruence). By advising on a minimum } \\
\text { standard of threshold behaviour and CARs, } \\
\text { SCIs mitigate risk. Both SCIs provide risk } \\
\text { assessment and management tools. } \\
\text { SociSense reported more of a balanced risk }\end{array}$ \\
\hline
\end{tabular}




\begin{tabular}{|c|c|c|c|}
\hline & & & $\begin{array}{l}\text { management approach which included suppliers } \\
\text { risk of being terminated, whereas InfoOrder } \\
\text { provided more perspectives from the buyer } \\
\text { side. The degree of a reputational risk focus } \\
\text { was more evident with InfoOrder whereas } \\
\text { SociSense considered supply chain disruption } \\
\text { risk if a non-compliance led to termination of a } \\
\text { supplier. }\end{array}$ \\
\hline $\begin{array}{l}\text { Capability } \\
\text { support }\end{array}$ & $\begin{array}{l}\text { "The use of the SAQ and accompanying CARs helps companies } \\
\text { to be able to respond to their own particular challenges but have } \\
\text { a common system that makes sense. It also allows them to } \\
\text { collaborate with other companies and reduce that duplication on } \\
\text { their suppliers" Head of Stakeholder Relations }\end{array}$ & $\begin{array}{l}\text { "I think most organisations are happy to be free } \\
\text { from too many rigorous standards or regulation } \\
\text { but there is definitely a desire to have some more } \\
\text { directional support. If there were some kind of set } \\
\text { standards, we could maybe work in a more } \\
\text { cohesive way and maybe achieve something } \\
\text { quicker. Trying to educate about best practice and } \\
\text { make corrective changes would be quicker with } \\
\text { standards or laws behind them. But overall, our } \\
\text { members are proud to be part of what we are } \\
\text { trying to achieve" Business Development } \\
\text { Manager } \\
\text { "We are here for one reason and we want to } \\
\text { empower the buyers and suppliers" Business } \\
\text { Development Manager }\end{array}$ & $\begin{array}{l}\text { SCIs support buyers and suppliers beyond } \\
\text { sustainability knowledge and into the 'doing' of } \\
\text { best practice through CARs. }\end{array}$ \\
\hline $\begin{array}{l}\text { Disintermediary } \\
\text { support }\end{array}$ & $\begin{array}{l}\text { "Although our database stores the SAQs, buyers and suppliers } \\
\text { often work with one another directly past the initial selection } \\
\text { phase, most often to work through the corrective action report, at } \\
\text { which point we can still be involved but their teams work more } \\
\text { closely" Supplier Engagement Manager }\end{array}$ & $\begin{array}{l}\text { "We want suppliers to be able to correct their } \\
\text { own actions alone eventually" Business } \\
\text { Relationship Officer }\end{array}$ & $\begin{array}{l}\text { SCIs support the bridging of the dyad as part of } \\
\text { the service offered to network members. }\end{array}$ \\
\hline $\begin{array}{l}\text { Service } \\
\text { development }\end{array}$ & $\begin{array}{l}\text { "We see our objective as driving sustainable supply chains and } \\
\text { improving conditions. We rely on our reputation to ensure repeat } \\
\text { use of our services next time a purchasing decision needs to be } \\
\text { made. However, we do not intend to be a sourcing platform" } \\
\text { Head of Stakeholder Relations }\end{array}$ & $\begin{array}{l}\text { "What we offer from the outset and what we } \\
\text { eventually end up delivering through building } \\
\text { better links positively impacts on business and } \\
\text { society overall. We are often asked back to work } \\
\text { with organisations" Business Relationship Officer }\end{array}$ & $\begin{array}{l}\text { SCIs use their position in original temporary } \\
\text { sourcing triad to get repeat work. }\end{array}$ \\
\hline $\begin{array}{l}\text { Behavioural } \\
\text { improvement }\end{array}$ & $\begin{array}{l}\text { "Especially in the wake of [factory disasters] there has been } \\
\text { resurgence in the importance of health and safety. And in some } \\
\text { of the research in the past year we are seeing recurring issues in } \\
\text { fire safety that are not being resolved over time. And in terms of } \\
\text { labour standards there are some areas where things are very } \\
\text { much improving like wages and working hours. But a lot of the }\end{array}$ & $\begin{array}{l}\text { "What we end up doing, is empowering buyers } \\
\text { and suppliers to make more effective global } \\
\text { sourcing choices" Stakeholder Manager }\end{array}$ & $\begin{array}{l}\text { CARs drive better behaviour. } \\
\text { Enhanced knowledge and improved capability } \\
\text { drives better behaviour. } \\
\text { Information sharing and goal congruence is } \\
\text { improved. } \\
\text { SCIs use their knowledge to anticipate }\end{array}$ \\
\hline
\end{tabular}


record keeping type elements remain huge challenges in parts of

the world. What we do see though is that issue areas do have

sustainability trends and priorities.

Behavioural improvement is the result of

resurgences. So at the moment we are seeing huge focus again

on health and safety because I think unfortunately some of these

tragedies remind people that we have not got there yet and the

job is not done. We have anticipated increased modern slavery

expectations and global development goal opportunities and pass

this on to our members" Stakeholder Manager 


\subsection{Role of the supply chain intermediary}

The case study results show the value of the SCIs' role in establishing a SSC. At the intermediation stage, the service element of the SCI seeks to utilise external networks to support more efficient and effective socially sustainable change to improve human welfare, as the SCIs were socially focused. The following constructs were identified as the role composition of the SCI for SSCM pursuit, reflecting its collaborative stance in the development of a triadic exchange: information transfer, knowledge development, risk management and capability support. The first proposition is:

Proposition 1. Sustainability SCIs add value to the prospective buyer-supplier dyads by playing a bridging role between the unconnected parties at the intermediation stage.

\subsubsection{Information transfer}

The first way that the SCI role adds value is through information transfer. Through the provision of information that flows through the bridge created by the SCI, both the buyer and supplier have access to opportunities for their respective businesses. For the suppliers, the SCI's platform provides a window from which they can display their sustainability credentials to a wide market, without having to duplicate the effort for each and every potential customer. For buyers, the SCI offers the possibility of checking suppliers' credentials, via their own standardised benchmarked criteria, without becoming engaged in costly and time-consuming one-to-one discussions. Proposition 1a identifies the first way SCIs add value to the buyer-supplier dyad by successfully bridging gaps between parties unknown to one another until they can operate without the SCI facilitation: 
Proposition 1a. Through their bridging role, SCIs facilitate sustainability-related information transfer and reduce information asymmetry within prospective buyer-supplier dyads.

\subsubsection{Knowledge development}

The second way that the SCI role adds value is through knowledge development. Ensuring that the commercial gains are available to each node in the sourcing triad, the SCI works with the suppliers to improve their capability and performance through CARs therefore enhancing their potential for exchange and supply chain improvement. SCIs can facilitate due diligence so that each partner has greater knowledge about the other's resources and reduce informational asymmetries. The intermediation stage was found to provide the opportunity for the SCI to add value through its information and best practice knowledge development. SCIs contribute to the knowledge that is developed by buyers and suppliers where the ambiguity of measures around sustainability dimensions is evident so that they understand what is expected of them and how sustainability may have competitive gains. In documents provided by SCIs, they communicate clearly the role of information transfer and knowledge development as a basis for cost effective collaboration. For example, InfoOrder advertise a "cost-effective electronic collection of ethical and responsible business information for selecting suppliers".

Proposition 1b. Through their bridging role, SCIs facilitate longer-term sustainability knowledge development between buyers and suppliers beyond the specific transaction partners.

\subsubsection{Risk management}

The SCI plays a key role in the sourcing triad through the supply risk management functions for which it takes responsibility and this is the third way that the SCI role adds value. The risk 
reduction to the triad is experienced through transparency of information, focus of hazardous behaviour and CARs, educating the supplier on improved behaviour to reduce poor practice that may lead to negative impacts in the supply chain. For example, if poor production planning was identified as a root cause of sudden overtime, the corrective action would need to show improved forecasting to ensure worker conditions improved through less unscheduled overtime. The transfer of best practice knowledge in this codified manner can aid suppliers in addressing barriers to improving their SSC performance and reducing reputational risk. From a buyer's perspective, it is anticipated that the measures provided by the SCI will give a full and reliable measure of the risk associated with the potential supplier based on the policies that the purchasing company is deploying.

Through the wider network in which the SCI is embedded, the value add is that it can access information on trends, opportunities and threats before other network members become aware. This proffers the SCI the potential to support changes in suppliers and buyers before issues arise from the wider environment, therefore avoiding adverse effects on the reputation and performance of the triad and the wider network. Examples include the introduction of the Modern Slavery Act or the Sustainable Development Goals.

Proposition 1c. Through their bridging role, SCIs help with the management of sustainability risks associated with information asymmetry and goal incongruence within prospective buyer-supplier dyads.

\subsubsection{Capability support}

The fourth way that the SCI role adds value is through capability support, which is offered by the SCIs and discussed in detail in the interviews. Extending this capability support to assisting with behavioural improvements of buyers and suppliers through CARs was crucial in this support because "We identify the risks and the sustainability issues including where [suppliers] can 
progress. We want to help the suppliers improve for the benefit of the chain as a whole rather than say 'that's it' for a non-compliance. We might look at corrective action reports which advise improvement programmes in factories that we slowly want to get to or master steps models, rather than just the number of non-compliances. We provide the guidance to improve sustainability behaviour in the chain. We facilitate the development of behavioural plans from suppliers at the selection phase. Buyers don't have the expertise to necessarily advise them on how at this stage but we can work together to provide this" (Business Relationship Officer, SociSense). SCIs may offer CARs based on the weaknesses derived from the assessment to stimulate suppliers' abilities and motivation. SCIs can assist with this corrective action making them valuable in the pursuit of social sustainability. Corrective actions facilitated by the SCI include improved labour standards such as freedom of association, collective bargaining, living accommodation, child workers, wages, working hours, discipline, grievance, health and safety standards including training, exposure to hazardous materials, emergency and procedures, and machinery safety. This approach also proffers suppliers an opportunity to demonstrate their social sustainability behaviour and intentions to collaborate with potential customers.

Proposition 1d. Through their bridging role, SCIs support an improvement in sustainability capabilities within prospective buyer-supplier dyads.

Therefore, at intermediation, the role of the SCI was found to be the delivery of the four constructs found in the data; information transfer, knowledge development, risk management and capability support. 


\subsection{Transient nature of SCI position}

Sustainability SCIs were found to have a high degree of facilitation between buyers and suppliers embarking on new SRP relationships. The SCI utilises a service providing position in the centre of the process between the buyer and supplier creating a triad. However, the results show that these sourcing triads are not permanent forms and change through the process of SRP. Three stages of sourcing triad were found during the process (see Figure 3), demonstrating that the role of the SCI is in a temporary triad that evolves and changes. The triad based on the original bridging position reflects the before/during sourcing stage (intermediation), post sourcing stage (disintermediation) and future sourcing facilitation (post-disintermediation) of the SCI in establishing SSCs at the supplier selection point. Therefore, it is not a permanent triad that has been formed, but a transient, temporary triad that evolves through the exchange. Once the buyer and supplier are linked by the SCI, bridge transfer occurs between the SCI and the buyer and supplier rendering their role redundant. Following the disintermediation, the SCI has postdisintermediation opportunities due to the previous roles held in the temporary triad.

During the disintermediation stages, the position of the SCI as the bridge in the network begins to diminish as the buyer and supplier begin to engage in direct contact. Through working to establish direct links, the two previously separated nodes evolve to interact with limited or no input of the SCI. Supporting the buyer and supplier to forge a link adds to the capability support reputation of the SCI with the original triad members and their wider industry interactions. The interviews provided insight into how the SCIs bridge the buyer and supplier's introduction to establish SSCM through "transfer of expertise and information of behaviours to improve social sustainability of suppliers which they wouldn't have the proficiency to tackle on their own" (Supplier Engagement Manager, SociSense) even though it leads to the bridge transfer, resulting in disintermediation. 
The loss of the SCI position through disintermediation enhances the SCIs influence in the future due to the perceived value add of its services post-disintermediation. Document analysis exhibited less evidence of service development as by doing so the SCI would de facto be announcing that they are a temporary measure. During interviews, service development during post-disintermediation is described as "repeat business with members in different exchanges, new members for new exchanges and other ways to assist members beyond selection requirements" (Business Development Manager, InfoOrder). Service development is thus the building up of additional capabilities to aid future triad activities through collaborative corrective actions or innovations. The success of connecting actors in the previous temporary triad provides a platform for buyer reengagement in future searches for other suppliers therefore, leading to the SCI being introduced into another temporary triad as a SCI. In SSCM where mutual goals for overall environmental and societal development are pursued, the triads demonstrate progress in the field where the SCI will adapt their business model through service development beyond sustainable supplier selection assistance. The service development opportunities such as supplier management capabilities or sustainable sourcing platform options are a positive step towards more SSCs and a positive impact on society.

Figure 3 shows the development of the sourcing triad from intermediation, disintermediation and post-disintermediation where the direct buyer-supplier link has been developed, yet there is reengagement of the SCI with previous actors from the original temporary triad as a result of pursuing new business (temporary triad 2 and 3). Thus, the SCI is engaged with new business in the industry as a result of enhanced reputation from the recent temporary intermediation that occurred. 
Proposition 2. The buyer-SCI-supplier triads dissolve after the intermediation stage (i.e., disintermediation) but their original success results in their reengagement in new triads at the post-disintermediation stage.

Figure 3: SCI role through stages of sourcing

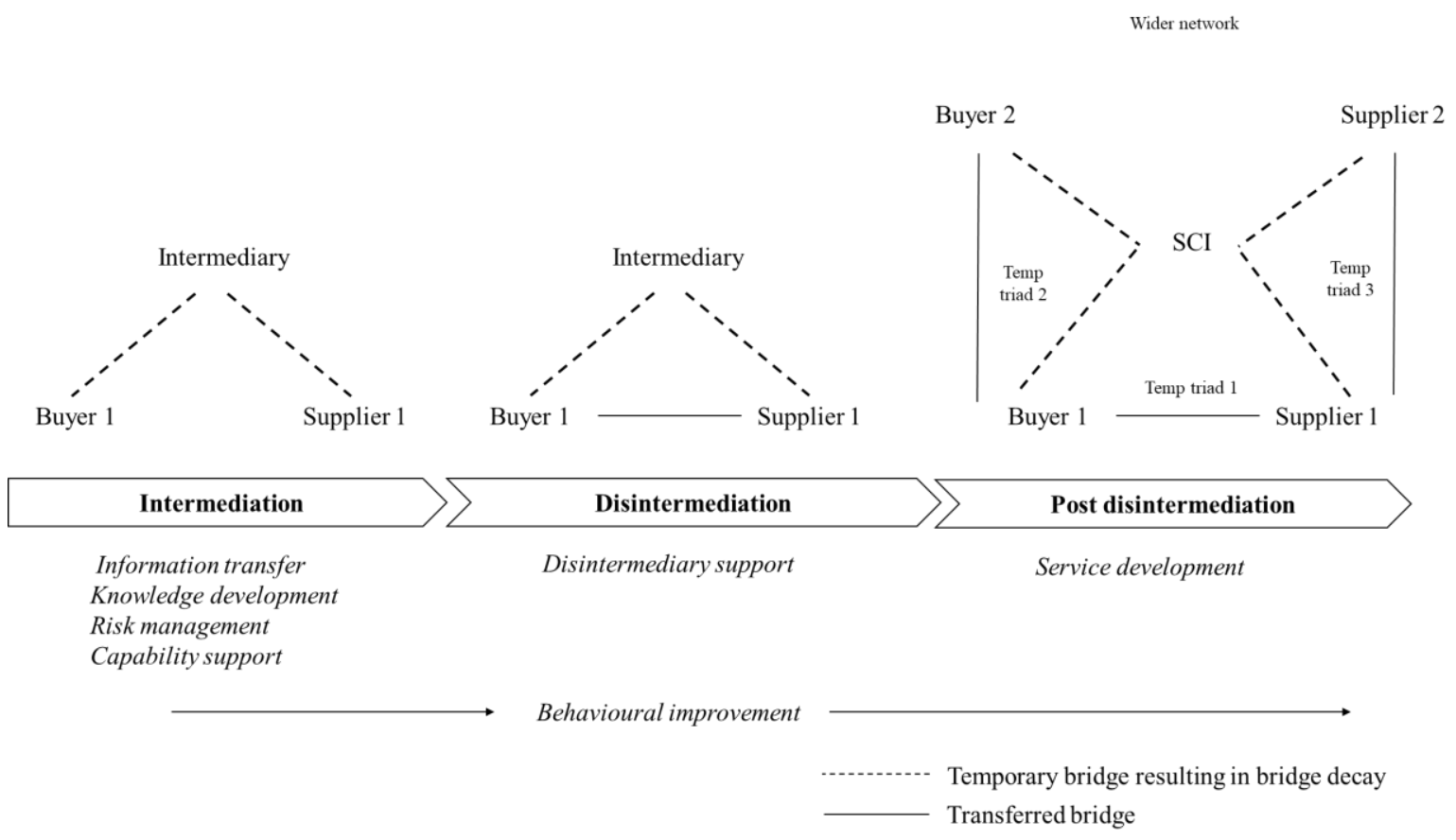

\subsection{Intended consequence of SCI role}

The overall network consequence of the value adding role of the SCI (information transfer, knowledge development, risk management and capability support) resulted in improved behaviour of both buyers and suppliers, impacting overall society positively. This is evidenced in the data using CARs to drive better behaviour, improved knowledge and capability, to ensure effective actions and information transfer which enhances symmetry and goal congruence. Additionally, SCIs use their knowledge to anticipate future market expectations and pass these to buyers and suppliers as well. For example, the stakeholder manager at InfoOrder reported that 
'we were successful at foreseeing the organisational requirements for modern slavery and able to pass these on to our members before the Act was passed'.

Proposition 3. SCIs' engagement in intermediation-disintermediation-post-intermediation cycles has spill over sustainability benefits to general buyer and supplier populations as well as to broader society.

\section{Theoretical Implications}

The paper contributes to our understanding of the role of the SCI in supporting the establishment of SSCM by examining an important phase of the formation of SSCs, at the point where buyers and suppliers are linked for the first time e.g. in the SRP arena. By using a SCI with specialist knowledge on best practice, buyers and suppliers are connected and encouraged to improve their sustainability pursuits. SCIs firstly align the sustainability aspirations of buyers and suppliers, and then facilitate further development in the quest for best practice through CARs and sustainability guidelines, to reduce the risk associated with opaque measurements and standards. For the establishment of SSCM to occur, organisations' knowledge and capabilities of sustainable best practices must be developed and shared within the supply chain, a process we know little about from the current literature (Busse et al., 2017; Hannibal and Kauppi, 2018). Wagner and Svensson (2010) and Xu et al. (2019) considered business immaturity as a reason for lack of progress, specifically found to be the lack of processes or instruments for its efficient introduction by Schneider and Wallenburg (2012), which this paper addresses through investigating the SCI role.

Through the facilitation of information transfer, the SCI supports other parties in the triad to develop problem-solving routines and inter-organisational learning; aspects of collaboration 
which are essential in enhancing the social performance of the supply chain (Sancha et al., 2016). The positive outcome of developing and facilitating direct links between buyer and suppliers enhances the value of the SCI and has positive benefits on SSCM results through its unique position in the supply chain and its willingness to drive change for environmental and societal benefits, reflecting its not-for-profit status. These SCI actions which support alignment, sharing of best practice and issue resolution provide insights into the "specific practices facilitating sustainability" (Nakamba et al., 2017:530), an area of research which is currently poorly represented in the supply chain literature. The processes which SCIs have developed and use to govern exchanges during the early establishment of a SSC, provide a pathway for organisations to follow in their initial developmental stages. For example, through information sharing, knowledge development, risk management and improving capability.

The value add of the SCI is to build links that deliver the needs of the buyer and supplier to form SSCs and instigate change where needed. This differs from the commercial pursuit of future exchange of businesses through repeat purchase. The not-for-profit approach of the SCI challenges the perspective that the buyer should control and coordinate all other actors in the triad (Johnson, 2004). Positioning the SCI as a broker that does not need to be tightly managed by the buyer in order to reduce opportunism and information asymmetry, broadens the understanding of governance in the temporary triad. Through their ability to harvest information from a broad range of sources, SCIs are able to maintain centrality in their network of suppliers by transferring knowledge and best practice trends amongst its members. This continual scanning for changes in the sustainability landscape by SCIs also provides critical information for buyers and suppliers as they develop their own standards and strategies, a bonus of organisations with a position that allows them to draw on both experience and foresight (Zaheer and Bell, 2005). This ability to identify changes and 
possible risks in the supply chain can also strengthen future trading possibilities for SCIs (Vanpoucke et al., 2017). Through focusing on the role and purpose of not-for-profit SCIs, in the SSC context, this research has revealed an alternative approach to governance controls and perspectives of managing the supply chain.

Purchasing partners such as SCIs have been neglected in the literature (Li and Choi, 2009; van der Valk and van Iwaarden, 2011; Chen et al., 2017). For the purchasing community, the movement in governance from buyer-led to SCI co-ordinated needs to be carefully considered as knowledge and information management increases in importance placing intermediaries at the nexus of the supply chain (Yan et al., 2015). SCIs chose to become involved in partnerships when the exchanges are temporary in nature, aiding the development of an understanding of why they actively transfer bridges and purposefully pursue their removal from the sourcing process, despite this being considered unstable by Roloff (2008). Initially, they have achieved their role of bridging the dyad and as sustainability considerations are diffused through the actors' behaviours, non-complying suppliers will be forced to improve their sustainability operations. Eventually the best practice of SSCM, although still developing, will infiltrate the industry (Villena and Gioia, 2018). Thus, it goes beyond learning for the network, and leads to behavioural improvement resulting in visibly enhanced SSCs.

Our findings have highlighted the unique role that not-for-profit SCIs perform in establishing a SSC. The role itself was executed in a dynamic environment with changes occurring in the triad and network as SSCM develops. This research has revealed the use of a triadic structure which is transient in nature rather than continuous on-going exchange. Research into temporary triadic structures which lead to disintermediation of the service provider is a shortfall in the supply chain literature (Choi and Wu, 2009). Within the SSC temporary triad, 
the position of the SCI altered as the links and collaboration between the buyer and supplier developed, in line with findings from Kim et al. (2011) and Villena and Gioia (2018) who proposed that networks should be characterised not by purposeful design, but should 'emerge'. Within the context of the temporary triad, the SCI position is designed to be transient and transferable but far from being a "negative" thing for the SCI as they lose their broker position ( $\mathrm{Li}$ and Choi, 2009), in our illustrative case studies, the establishment of direct link between buyer and supplier was a "positive" step from the SCIs' perspective as it solidifies their route to delivering future value, enhanced through disintermediary support.

Through strengthening the exchange between the two previously remote nodes in the network through SRP, the SCI makes itself redundant from the triad. But, disintermediation represented a successful engagement for the SCI and thus the development of a SSC. The positive action along with the increased knowledge of good practice that is derived from the links strengthens the SCI and attractiveness for future opportunities. The temporary triad structure that has developed within the context of SSC highlights the need for researchers to consider multiple perspectives when developing theoretical frameworks based on temporary roles. The role of the SCI in establishing and co-ordinating the SSC triad illustrates the importance of comprehending all of the partners' perspectives in the structure. According to the SCI, their intended consequence is improved sustainability behaviour of both buyers and suppliers which has a positive effect on social welfare overall through enhanced knowledge and stronger cooperation and coordination.

\section{Managerial Implications}

Using a sustainability SCI for SRP has led to the development of temporary triads between the buyer, SCI and supplier. The research highlights that the SCI's role changes throughout 
the exchange as it moves from being a broker within a temporary triad to eventually being reengaged in another triad as a result of its original position. Previous research indicates that buyers will develop measures and controls to manage the exchange with SCIs to minimise the risk associated with the SCI position for on-going triadic exchanges (Johnson, 2004; Zhang et al., 2015). However, providing clarity on the strategic objectives of the SCI, in temporary triads, could alleviate costs for the buyer and enhance the frequency and efficiency of triadic exchanges for SCIs. Identifying the contribution delivered by the SCI as a broker, in terms of information flow, best practice knowledge exchange, risk management, capability support and overall resulting behavioural improvement could enhance the effectiveness of the SSC operation by supporting buyers in resolving the conundrum of the most appropriate way to assess new suppliers. Additionally, SCIs can benefit from identifying future income streams that their knowledge of the supply chain and brokerage skills can deliver. The challenge for the SCI is to develop other opportunities without undermining the neutrality that the temporary triad broker position warrants.

\section{Limitations and Future Directions}

Although our findings are based on two sustainability SCIs operating in the market, we acknowledge that these studies are limited in terms of both their sample and context. Firstly, the sample is small as the global sustainability SCI market is still in a growth stage. Pursuing a more SSC will continue to become salient in business agendas and increase the number of SCIs active in the market, especially for maintaining a SSC through legacy suppliers. Our research has focused on supplier selection, but management of current suppliers is also critical (Ghijsen et al., 2010; Sancha et al., 2015). Secondly, by investigating the role of the SCI in the triad between buyers, SCIs and suppliers, both the triad view from the buyer and supplier perspective and the full network view is neglected (Dubois, 2009). It may be fruitful 
for further studies to consider the dissemination activities beyond the first-tier supplier to sub-suppliers in the multi-tiered network and how these are facilitated for SSCM. These limitations of our study point towards promising directions for future research.

\section{Conclusion}

The research has explained the role of the sustainability SCI providing insights into how that role changes and why, as the SCI disintermediates itself from the buyer and supplier and reintegrates back into the network as the SSC evolves. The SCI role facilitates the establishment of a SSC through information transfer, knowledge development, risk management and capability support, in a temporary triad structure, resulting in behavioural improvement across the supply chain for the benefit of wider society. Along with Hannibal and Kauppi (2018), our study is one of few to utilise empirical data collected across global SCIs rather than the buyer and/or supplier.

The paper contributes to our understanding of SSCM by identifying a pathway which organisations can follow to establish a SSC, a call made by Akhavan and Beckmann (2017). By using a SCI with specialist knowledge on best practice, buyers and suppliers are connected and encouraged to improve their sustainability pursuits. SCIs firstly align the sustainability aspirations of buyers and suppliers and can then facilitate further development in the quest for best practice through CARs and sustainability guidelines to reduce the risk and challenges of opaque measurements and standards. The transient nature of the temporary triad provides more future opportunity to do business, not less. Understanding the way of working across the three stages of the process for all actors enhances the SCIs' ability to deliver further value resulting in societal benefits from improved social sustainability behaviours across the supply network. 


\section{Appendices}

Appendix A:

Interview Protocol

Supply chain intermediary interview questions

- What is sustainability in the context of purchasing?

- How can sustainability in supply chains be achieved? What are the challenges with measuring the results?

- Why are firms engaging in sustainability behaviour?

- To what extent do you work with other intermediaries to get a sector wide approach for criteria? Is it important that each user tailors it individually? How is that possible with a one size fits all approach (SAQ)?

- To what extent do intermediaries listen when users request changes to standardised tools?

- Do you think there are issues with training the suppliers to use the tools?

- Is it difficult to have no set standards and limited regulation or does industry welcome the flexibility in that?

- How do you decide on the criteria? Is it ranked? Are the measures still maturing?

- How involved are buyers/suppliers in the social and environmental measures of their supply chains?

- What have been the 'frustrations' and 'gaps' in the pursuit of sustainable supply chains?

- Please describe the information transfer process and the benefits to parties involved.

- Why are your members using your tool? Are different industries using the same information out of that exchange? Are they extracting relevant parts only? How are they using the information?

- How does your management of buyers and suppliers differ?

- What is the benefit of working with your organisation and using your resources?

- How does your support evolve through the sourcing process?

- How important is sustainability improvement of buyers and suppliers?

- In what ways do you employ augmented services once an exchange has occurred?

- Is sustainability reporting and membership simply a "public relations tool"?

\section{Appendix B:}

Table III: Coding Kappa Coefficients

All Kappa coefficient agreements were above 0.62 (substantial agreement). The coding means of alternative data types were highly acceptable at over 0.76 . Across the codes, $50 \%$ near perfect agreement was found on intermediation constructs, of which all showed no less than 0.73 for a data source (high substantial agreement).

\begin{tabular}{|c|c|c|c|}
\hline \multirow{2}{*}{ Code } & \multicolumn{3}{|c|}{ Kappa Agreement } \\
\hline & Document analysis & Interview analysis & TOTAL MEAN \\
\hline Information transfer & 0.912 & 0.729 & 0.821 \\
\hline Knowledge development & 0.789 & 0.899 & 0.844 \\
\hline Risk management & 0.767 & 0.743 & 0.755 \\
\hline Capability support & 0.787 & 0.800 & 0.794 \\
\hline Behavioural improvement & 0.766 & 0.701 & 0.734 \\
\hline Disintermediary support & 0.623 & 0.720 & 0.672 \\
\hline Service development & 0.693 & 0.710 & 0.702 \\
\hline Mean & 0.762 & 0.757 & 0.761 \\
\hline
\end{tabular}


This research did not receive any specific grant from funding agencies in the public, commercial, or not-for-profit sectors.

Acknowledgements - we extend out thanks to Dr Amanda Lee who provided critical guidance on some methodological aspects of our paper. We would also like to recognise the EurOMA Publishing Workshop held in Barcelona where a much earlier draft of this paper was presented and feedback received.

\section{References}

Akhavan, R. M., Beckmann, M., 2017. A configuration of sustainable sourcing and supply management strategies, Journal of Purchasing and Supply Management, 23, 2, pp. 137-151.

Busse, C., Meinlschmidt, J., Foerstl, K., 2017. Managing information processing needs in global supply chains: A prerequisite to sustainable supply chain management. Journal of Supply Chain Management, 53, 1, pp. 87-113.

Chen, L., Zhao, X., Tang, O., Price, L., Zhang, S. Zhu, W., 2017. Supply chain collaboration for sustainability: A literature review and future research agenda. International Journal of Production Economics.

Choi, T.Y., Wu, Z., 2009. Taking the leap from dyads to triads: Buyer-supplier relationships in supply networks. Journal of Purchasing and Supply Management. 159, 4, pp. 263-266.

Cohen, J., 1960. A coefficient of agreement for nominal scales. Educational and Psychological Measurement, 20, 1, pp. 37-46.

Cole, R., 2017. Turning Point. Getting their wings: Angel agents live on-Supplier stewards in sustainable enterprise. Journal of Corporate Citizenship, 67, pp. 3-11.

Cole, R., Aitken, J., 2019. Selecting suppliers for socially sustainable supply chain management: Postexchange supplier development activities as pre-selection requirements. Production Planning \& Control, In press.

Corley, K.G., Gioia, D. A., 2004. Identity ambiguity and change in the wake of a corporate spin-off. Administrative Science Quarterly, 49, pp. 173-208.

Davey, J.W., Gugiu, P.C., Coryn, C.L., 2010. Quantitative methods for estimating the reliability of qualitative data. Journal of MultiDisciplinary Evaluation, 6, 13, pp. 140-162.

Dubois, A., 2009. Comment on 'Taking the leap from dyads to triads: Buyer-supplier relationships in supply networks' by Choi and Wu: To leap or not to leap: Triads as arbitrary subsets of networks of connected dyads", Journal of Purchasing and Supply Management, 15, 4, pp. 267-268.

Dyer, J.H., Hatch, N.W., 2006. Relation-specific capabilities and barriers to knowledge transfers: creating advantage through network relationships. Strategic Management Journal, 27, 8, pp. 701-719.

Foerstl, K., Meinlschmidt, J., Busse, C., 2018. It's a match! Choosing information processing mechanisms to address sustainability-related uncertainty in sustainable supply management. Journal of Purchasing and Supply Management.

Fung, P. K., Chen, I. S., Yip, L. S., 2007. Relationships and performance of trade intermediaries: an exploratory study. European Journal of Marketing, 41, 1/2, pp. 159-180.

Garetti, M., Taisch, M., 2012. Sustainable manufacturing: trends and research challenges. Production Planning \& Control, 23, 2-3, pp. 83-104.

Genovese, A., Lenny Koh, S. C., Bruno, G., Esposito, E., 2013. Greener supplier selection: state of the art and some empirical evidence. International Journal of Production Research, 51, 10, pp. 2868-2886.

Ghijsen, P. W. T., J. Semeijn, Ernstson, S., 2010. Supplier satisfaction and commitment: The role of influence strategies and supplier development., Journal of Purchasing and Supply Management, 16, 1, pp. 17-26.

Gioia, D. A., Corley, K. G., Hamilton, A. L., 2013. Seeking Qualitative Rigor in Inductive Research: Notes on the Gioia Methodology. Organizational Research Methods, 16, 1, pp. 15-31.

Hannibal, C., Kauppi, K., 2018. Third party social sustainability assessment: Is it a multi-tier supply chain solution? International Journal of Production Economics.

Hartmann, J. and Moeller, S. 2014. Chain liability in multitier supply chains? Responsibility attributions for unsustainable supplier behaviour. Journal of Operations Management, 32, 5, pp. 281-294.

Huq, F.A., Chowdhury, I.N., Klassen, R.D., 2016. Social management capabilities of multinational buying firms and their emerging market suppliers: An exploratory study of the clothing industry. Journal of Operations Management, 46, pp. 19-37. 
Hutchins, M.J., Sutherland, J.W., 2008. An exploration of measures of social sustainability and their application to supply chain decisions. Journal of Cleaner Production, 16, 15, pp. 1688-1698.

ITC Standards Map (2019), "Sustainability standards", available at: http://www.intracen.org/itc/marketinfo-tools/voluntary-standards/standardsmap/ (accessed 14 February 2019).

Jacobs, B., \& Singhal, V. R., 2017, "The effect of the Rana Plaza disaster on shareholder wealth of retailers: Implications for sourcing strategies and supply chain governance. Journal of Operations Management, 49, pp. 52-66.

Johnson, J.D., 2004. The emergence, maintenance, and dissolution of structural hole brokerage within consortia. Communication Theory, 14, 3, pp. 212-236.

Ketokivi, M., Choi, T., 2014. Renaissance of case research as a scientific method. Journal of Operations Management, 32, 5, pp. 232-240.

Kim, Y., Choi, T. Y., Yan, T., Dooley, K., 2011. Structural investigation of supply networks: A social network analysis approach. Journal of Operations Management, 29, 3, pp. 194-211.

Kim, S., Wagner, S. M., \& Colicchia, C., 2019. The impact of supplier sustainability risk on shareholder value. Journal of Supply Chain Management.

Landis, J.R. and Koch, G.G., 1977. The measurement of observer agreement for categorical data. Biometrics., 33, 1, pp. 159-174.

Leire, C., Mont, O., 2010. The implementation of socially responsible purchasing. Corporate Social Responsibility and Environmental Management, 17, 1, pp. 27-39.

Li, M. and Choi, T.Y., 2009. Triads in services outsourcing: bridge, bridge decay and bridge transfer. Journal of Supply Chain Management, 45, 3, pp. 27-39.

Maignan, I., B. Hillebrand, McAlister, D., 2002. Managing socially-responsible buying: how to integrate non-economic criteria into the purchasing process. European Management Journal, 20, 6, pp. 641-648.

McCutcheon, D., Meredith, J., 1993. Conducting case study research in operations management. Journal of Operations Management, 11, 3, pp. 239-256.

Meredith, J., 1998. Building operations management theory through case and field research. Journal of Operations Management, 16, 4, pp. 441-54.

Modi, S. B., Wiles, M. A., Mishra, S., 2015. Shareholder value implications of service failures in triads: The case of customer information security breaches. Journal of Operations Management, 35, 21-39.

Nakamba, C.C., Chan, P.W., Sharmina, M., 2017. How does social sustainability feature in studies of supply chain management? A review and research agenda. Supply Chain Management: An International Journal, 22, 6, pp. 522-541.

Obstfeld, D., 2005. Social networks, the tertius iungens orientation, the involvement in innovation. Administrative Science Quarterly, 50, 1, pp. 100-130.

Park-Poaps, H., Rees, K., 2010. Stakeholder forces of socially responsible supply chain management orientation. Journal of Business Ethics, 92, 2, pp. 305-322.

Paulraj, A., 2011. Understanding the relationships between internal resources and capabilities, sustainable supply management and organizational sustainability. Journal of Supply Chain Management, 47, 1, pp. 19-37.

Ridder, H. G., Hoon, C., McCandless Baluch, A., 2014. Entering a dialogue: Positioning case study findings towards theory. British Journal of Management, 25, 2, pp. 373-387.

Rodriguez, J., Gimenez Thomsen, C., Arenas, D., 2016a. Cooperative initiatives with NGOs in socially sustainable supply chains: How is inter-organizational fit achieved? Journal of Cleaner Production, 137.

Rodriguez, J., Gimenez Thomsen, C., Arenas, D., Pagell, M., 2016b. NGOs' Initiatives to enhance social sustainability in the supply chain: Poverty alleviation through supplier development programs. Journal of Supply Chain Management, 52, 3, pp. 83-108.

Roloff, J., 2008. Learning from multi-stakeholder networks: issue-focused stakeholder management. Journal of Business Ethics, 82, 1, pp. 233-250

Sancha, C., Longoni, A., Giménez, C., 2015. Sustainable supplier development practices: drivers and enablers in a global context. Journal of Purchasing and Supply Management, 21, 2, pp. 95-102.

Sancha, C., Gimenez, C., Sierra, V., 2016. Achieving a socially responsible supply chain through assessment and collaboration", Journal of Cleaner Production, 112, pp. 1934-1947.

Saunders, M.N. and Townsend, K., 2016. Reporting and justifying the number of interview participants in organization and workplace research. British Journal of Management, 27, 4, pp. 836-852.

Schneider, L., Wallenburg, C.M., 2012. Implementing sustainable sourcing-Does purchasing need to change? Journal of Purchasing \& Supply Management, 18, 4, pp. 243-257. 
Seuring, S., Müller, M., 2008, From a literature review to a conceptual framework for sustainable supply chain management. Journal of Cleaner Production, 16, 15, pp. 1699-1710.

Stevenson, M., Cole, R., 2018. Modern slavery in supply chains: a secondary data analysis of detection, remediation and disclosure. Supply Chain Management: An International Journal, 12, 3, pp. 81-99.

Van der Valk, W., Van Iwaarden, J., 2011. Monitoring in service triads consisting of buyers, subcontractors and end customers. Journal of Purchasing and Supply Management, 17, 3, pp. 198-206.

Vanpoucke, E., Vereecke, A., Muylle, S., 2017. Leveraging the impact of supply chain integration through information technology. International Journal of Operations \& Production, 37, 4, pp. 510-530.

Vedel, M., Ellegaard, C., 2013. Supply risk management functions of sourcing intermediaries: an investigation of the clothing industry. Supply Chain Management: An International Journal, 18, 5, pp. 509-522.

Villena, V. H., Gioia, D. A., 2018. On the riskiness of lower-tier suppliers: Managing sustainability in supply networks. Journal of Operations Management. 64, pp.65-87.

Wagner, B., Svensson, G., 2010. Sustainable supply chain practices: research propositions for the future. International Journal of Logistics Economics and Globalisation, 2, 2, pp. 176-186.

Wang, J. J., Li, J. J., Chang, J., 2016. Product co-development in an emerging market: The role of buyersupplier compatibility and institutional environment. Journal of Operations Management, 46, pp. 6983.

Wilhelm, M. M., Blome, C., Bhakoo, V., Paulraj, A., 2016. Sustainability in multi-tier supply chains: Understanding the double agency role of the first-tier supplier. Journal of Operations Management, 41, pp. $42-60$.

Wuyts, S., Rindfleisch, A., Citrin, A., 2015. Outsourcing customer support: The role of provider customer focus. Journal of Operations Management, 35, pp. 40-55.

Wynstra, F., Spring, M., Schoenherr, T., 2015. Service triads: a research agenda for buyer-suppliercustomer triads in business services. Journal of Operations Management, 35, pp. 1-20.

Xu, L., Shi, X., Xie, Y., Tsai, S. B., 2019. Corporate Social Responsibility-Based Supplier Selection Process in Sustainable Supply Chains. In Corporate Social Responsibility: Concepts, Methodologies, Tools, and Applications (pp. 155-172). IGI Global.

Yan, T., Choi, T.Y., Kim, Y., Yang, Y., 2015. A theory of the nexus supplier: A critical supplier from a network perspective. Journal of Supply Chain Management, 51, 1, pp. 52-66.

Yin, R.K., 2003. Case Study Research: Design and Methods. Third edition. Sage Publications, Inc., Thousand Oaks, CA.

Zaheer, A., Bell, G.G., 2005. Benefiting from network position: firm capabilities, structural holes, and performance. Strategic Management Journal, 26, 9, pp. 809-825.

Zhang, J.J., Lawrence, B., Anderson, C.K., 2015. An agency perspective on service triads: Linking operational and financial performance. Journal of Operations Management, 35, pp. 56-66.

Zorzini, M., Hendry, L.C., Huq, F.A., Stevenson, M., 2015. Socially responsible sourcing: reviewing the literature and its use of theory. International Journal of Operations and Production Management, 35, 1, pp. 60-109. 